\title{
Thermal Industrial COMFort Analysis ACCORDING TO DIFFERENT REGULATIONS
}

\author{
BENITO, P.; GONZALEZ-GAYA, C \& SEBASTIAN, M.A.
}

Abstract: A comparative analysis between the rules and regulations on Thermal Comfort applied in Argentina and Spain is presented. The most important documents on the subject are analyzed in both regulations. This analysis shows that there are regulations related to constructive requirements that are based on optimizing the thermal resistance of walls, floors and ceilings. But there is a regulatory and calculation vacancy, in relation to thermal comfort in industrial buildings. Not only must the design parameters be taken into account, but also the type of activity, time range, time of year, and geographical region. In Argentina, two case studies were carried out obtaining recommended values for dry bulb temperature and relative humidity, based on the variables mentioned. When corroborating the benefits of using these values for each zone and activity, the possibility of obtaining an algorithm that satisfies this need is analyzed. The importance of having these parameters is to optimize the climate of the work environment that leads to a decrease in occupational risks. This optimization brings with it other benefits no less important: the saving of energy, the increase of the performances and procures a better quality of life.

Keywords: thermal comfort, relative humidity, temperature, occupational risk
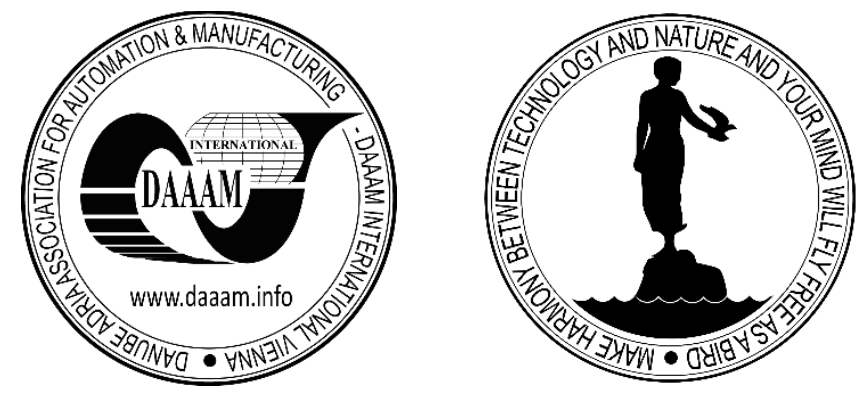

Authors' data: Benito, P[atricia]*; González-Gaya, C [ristina] **; Sebastián, M [iguel A.] **, *Universidad Nacional de Educación a Distancia (UNED), Universidad de Morón (UM-SECyT), Cabildo 134, Morón, Argentina, ** Universidad Nacional de Educación a Distancia (UNED), Department of Manufacturing Engineering, C/Juan del Rosal 12, 28040, Madrid, España, pbenito16@alumno.uned.es, cggaya@ind.uned.es, msebastian@ind.uned.es

This Publication has to be referred as: Benito, $\mathrm{P}$ [atricia]; Gonzalez Gaya, C[ristina] \& Sebastian, M[iguel] A[ngel] (2019). Thermal Industrial Comfort Analysis According to Different Regulations, Chapter 04 in DAAAM International Scientific Book 2019, pp.043-054, B. Katalinic (Ed.), Published by DAAAM International, ISBN 978-3-902734-24-2, ISSN 1726-9687, Vienna, Austria

DOI: $10.2507 /$ daaam.scibook.2019.04 
Benito, P.; Gonzalez Gaya, C. \& Sebastian, M. A.: Thermal Industrial Comfort Ana...

\section{Introduction}

The search for the best levels of work comfort and the implementation of the means to achieve them is an important part in the prevention of occupational risk. Generating an adequate work environment for the development of activities, promoting greater welfare for employees and operators, is one of the ways that reduces labor risk, increases personal performance and improves their quality of life.

The ASHRAE (American Society of Heating Engineers, Refrigeration and Air Conditioning), with the collaboration of various universities and official entities made experiences on the reactions of different people under different conditions of temperature, relative humidity and air movement. These results allowed to elaborate a comfort diagram that relates the psychrometric conditions with the human reaction.

The Fanger method published in the British Journal of Industrial Medicine (1973) assesses thermal comfort based on the Estimated Average Vote (PMV) and the Percentage of Dissatisfied Persons (PPD). The estimation of the Average Vote is made based on the insulation of the clothes, the Metabolic Rate and the characteristics of the environment (temperature, radiant temperature, relative humidity and air speed). This method, called physiological model, was developed in controlled chambers with young people at rest and of European or North American origin and allows to determine the percentage of people dissatisfied with the environment.

On the other hand, the adaptive models: Humphreys (1976), De Dear and Brager (1998) take into account the external climate to determine the preferences of interior comfort, where the person is not a passive receiver, but together with the environment forms a dynamic system. But these two theoretical approaches (Gómez-Azpeitia, L. et al, 2007) have not been able to give an answer to establish the design parameters of the air conditioning installations. The tables and / or graphs of temperature of dry bulb, relative humidity and air velocity that are applied, are obtained by methods and experiences carried out in countries whose climates, activities and working times are different.

By using these parameters, industrial facilities are adapting to another reality, leaving aside regional habits, local climate characteristics and cultural adaptation in terms of how the graduality of comfort levels is considered. Therefore, some questions arise to this problem: a) what are the thermal comfort levels specific to the working and climatic conditions of a region? b) do the working conditions improve using these specific comfort levels as design parameters? c) do the thermal comfort regulations in industrial areas contemplate these regional variables, the different activities, work time and seasons of the year?

In this stage, a bibliographic review of the norms and regulations on industrial thermal comfort applied in Argentina and Spain has been carried out. For this, the following analysis documents have been considered:

\subsection{Spanish regulations:}

- Regulation of Thermal Installations in Buildings (RITE), 2007-BOE 207

- Standard UNE-EN-ISO 7730-2005.

- NTP 74: Thermal comfort - Fanger method for evaluation. 
- NTP 501: Thermal environment and local thermal insufficiency. National Institute for Occupational Safety and Health, 1998.

- Occupational Risk Prevention Law (LPRL) - Ministry of Labor and Social Affairs: Royal Decree 486/1997, April 14, (BOE -April 23, 1997).

\subsection{Argentine regulations:}

- Law 13059/03 on Energy Saving of the Province of Buenos Aires, regulated by Decree No. 1030/10, and whose regulations to be complied with are standardized by the Argentine Institute for Standardization and Certification (IRAM).

- Law No. 4458 on Standards of thermal conditioning in the construction of buildings and whose specifications were included in the Building Code of the City of Buenos Aires.

- Law No. 19587 on Occupational Safety and Health and its Regulatory Decree N $^{\circ}$ 351/79.

- IRAM-ISO 7730 standard - Ergonomics of the thermal environment - Analytical determination and interpretation of thermal comfort using calculation of the PMV and PPD indices and local thermal comfort criteria (ISO 7730:2005)

\section{Comparative analysis of standards and regulations}

The first document to be analysed, the Regulation of Thermal Installations in Buildings (RITE) -BOE 207- is a measure of development of the Action Plan of the energy saving and efficiency strategy in Spain (2005-2007).

Its focus is on benefits or objectives as opposed to the traditional approach of prescriptive regulations. It indicates the requirements that thermal installations must meet but does not require the use of a certain technique or material, nor does it prevent the use of new technologies, allowing the application of innovative solutions.

This regulation constitutes the normative frame that regulates the demands of energetic efficiency and of safety the thermal installations of the buildings are to fulfill, and establishes in its Part I - General Provisions, art. 2, Scope of application- that: "For the purposes of the application of the RITE, fixed installations for air conditioning (heating, cooling and ventilation) and for the production of hot water will be considered as thermal installations, aimed at meeting the demand for people's thermal comfort and hygiene.” (Boletín Oficial del Estado (Official State Gazette) 207, 2007, p.35934)

Moreover, in Part II - Technical Instructions (IT- Spanish acronym), it is established that the application scope is that indicated in the above-mentioned art. 2 and that the verification process of the standard contemplates the quality requirement of the thermal environment, where operating temperature, relative humidity and average air speed are stated. According to the IT 1.4.1.1.2, the interior design conditions of the air conditioning facilities are set "based on the metabolic activity of the people, their clothing grade and the estimated percentage of people dissatisfied (PPD) ..." (Boletín Oficial del Estado 207, 2007, p.35945).

It provides the interior design conditions, for people with sedentary metabolic activity of 1.2 met, with clothing grade 0.5 clo in summer and 1 clo in winter, with an estimated percentage of dissatisfied between $10 \%$ and $15 \%$. 
Benito, P.; Gonzalez Gaya, C. \& Sebastian, M. A.: Thermal Industrial Comfort Ana...

The range of temperatures and relative humidity indicated is broad. For other conditions of metabolic activity, different clothing grade and for other PPD, the application of the UNE-EN ISO 7730 standard is indicated.

The UNE-EN ISO 7730 standard, Ergonomics of the thermal environment (ISO 7730: 2005), bases the thermal comfort analysis on Fanger Method, which was originally published in the British Journal of Industrial Medicine in 1973, and used as a recommendation in the NTP 74: Thermal Comfort: Fanger's method for its evaluation, from the National Institute of Occupational Safety and Health (Spain) (INSHT, 1983). The main aspects of the method are exposed. It assesses the state of thermal comfort, basing on the Predicted Mean Vote (PMV) and the Percentage of People Dissatisfied (PPD). The estimation of the Mean Vote is made by taking as a basis the clothing insulation, the metabolic rate and the environment characteristics (temperature, radiant temperature, relative humidity and air speed). This index allows determining the percentage of people dissatisfied with the environment (Fanger, 1973).

Also, the NTP 501, Thermal environment: Local Thermal Discomfort (INSHT, 1998), explains that although in Fanger's work (NTP 74) two conditions must be met for people to manifest satisfaction with the thermal environment: a) thermal balance and $b$ ) temperature of the skin and amount of exudation between certain limits, there may still be local discomfort due to air currents, asymmetry of radiant planes, contacts with cold or hot surfaces and vertical differences in temperatures. This recommendation leads to the need to take into account the last variables mentioned, in addition to those considered by Fanger.

Law 31/1995 of November 8 on Prevention of Occupational Risks-BOE 269, of November 10, 1995- Last modification: December 29, 2014 (Reference: BOE-A-199524292) - Edition updated at 13 March 2019, it has the purpose of: "determining the basic body of guarantees and responsibilities required to establish an adequate level of protection of the workers' health against the risks arising from working conditions; this within the framework of a coherent, coordinated and effective policy of prevention of occupational risks." (Boletín Oficial del Estado 269, 1995, 5).

The regulatory standard that deals with the issue in question is the Royal Decree 486/1997 of April 14, (BOE of April 23, 1997), where the minimum occupational safety and health provisions are stated. In its annex III, Environmental conditions of the workplace, it establishes that in closed places the following conditions must be fulfilled: "In closed working areas, the following conditions must be specifically met: a) The temperature of the premises where sedentary work is carried out, typical of offices or similar, will be between 17 and $27^{\circ} \mathrm{C}$. The temperature of the rooms where light work is carried out will be between 14 and $25^{\circ} \mathrm{C}$. b) The relative humidity will be between 30 and 70 percent, except in places where there exist risks of static electricity in which the lower limit will be 50 percent. c) Workers shall not be exposed frequently or continuously to air currents whose speed exceeds the following limits: 1 . Work in non-hot environments: $0.25 \mathrm{~m} / \mathrm{s}$. 2. Sedentary work in hot environments: 0.5 $\mathrm{m} / \mathrm{s}$. 3rd Non-sedentary work in hot environments: $0.75 \mathrm{~m} / \mathrm{s}$. These limits do not apply to air currents expressly used to avoid stress in intense heat exposures, nor to air conditioning currents, for which the limit will be $0.25 \mathrm{~m} / \mathrm{s}$ in the case of sedentary jobs and of $0.35 \mathrm{~m} / \mathrm{s}$ in other cases." (Boletín Oficial del Estado, 1997, 70). 
It can be observed that this regulation does not contemplate the moderate and/or strong work that can occur in the industry and only provides recommendations in ranges of temperature and relative humidity.

If the Argentine regulations are analyzed, there is a National Law of Occupational Safety and Health (Law No. 19587) and its Regulatory Decree No. 351/79. Its Annex II (Annex replaced by Annex III of the Resolution No. 295/2003 of the Ministry of Labor, Employment and Social Security -B.O. 21/11/2003) refers only to Thermal Stress.

On the other hand, there are regulations in the provincial area or in the Autonomous City of Buenos Aires (CABA), such as:

- Law 13059/03 of Thermal Conditioning of Buildings of the Province of Buenos Aires, regulated by Decree No. 1030/10, and whose regulations to be complied with are standardized by the Argentine Institute for Standardization and Certification (IRAM).

- Law No. 4458 on Standards of thermal conditioning in the construction of buildings and whose specifications were included in the Building Code of the City of Buenos Aires.

The regulatory Decree 1030/10 of the Law 13059/03 (Boletín Oficial de la Provincia de Buenos Aires $\mathrm{N}^{\circ}$ 26406, 2010) in its Annex I, states the regulations, scope and dispositions of design in buildings for human habitation.

The regulations in force to be fulfilled are the following:

1.1. IRAM Standard No. 11549. Thermal insulation of buildings. Vocabulary.

1.2. IRAM Standard No. 11601. Thermal insulation of buildings. Thermal properties of construction materials. Calculation method of the total thermal resistance.

1.3. IRAM Standard No. 11603. Thermal insulation of buildings. Bioenvironmental classification of the Argentine Republic.

1.4. IRAM Standard No. 11604. Thermal insulation of buildings. Energy saving in heating. Heat loss volumetric $\mathrm{G}$ coefficient.

1.5. IRAM Standard $\mathrm{N}^{\circ} 11605$. Thermal insulation of buildings. Living conditions in homes. Maximum admissible values of Thermal Transmittance "K" (maximum values corresponding to Level B).

1.6. IRAM Standard $\mathrm{N}^{\circ} 11625$. Thermal insulation of buildings. Verification of the risk of condensation of surface and interstitial water vapor in central drains.

1.7. IRAM Standard $\mathrm{N}^{\circ} 11630$. Thermal insulation of buildings. Verification risk of interstitial and superficial condensation in singular points.

The Law No. 4458, enacted on December 13, 2012 and published in the Boletín Oficial of the Autonomous City of Buenos Aires (BOCABA No. 4142 of 04/30/2013), states as requirements the same IRAM Standards as the Province of Buenos Aires, plus the ones detailed below:

- IRAM Standard $\mathrm{N}^{\circ}$ 11659-1. Thermal insulation of buildings. Verification of its hydrothermal conditions. Energy saving in refrigeration. Part 1: vocabulary, definitions, tables and data to determine the summer heat load. 
Benito, P.; Gonzalez Gaya, C. \& Sebastian, M. A.: Thermal Industrial Comfort Ana...

- IRAM Standard $\mathrm{N}^{\circ} 11659-2$. Thermal conditioning of buildings. Verification of its hydrothermal conditions. Energy saving in refrigeration. Part 2: buildings for housing.

- IRAM Standard No. 11900. Labeling of Energy Efficiency of Heating for Buildings.

The normative requirements take into consideration the constructive requirements in terms of the thermal resistance of walls, floors and ceilings, and the energy saving of buildings. It can be seen that they do not specifically refer to industrial buildings. In addition, there exists the IRAM-ISO 7730 standard: Ergonomics of the thermal environment, but it is not required in the Argentine regulations analyzed, unlike Spain where it is considered in the RITE.

\section{Problem formulation}

The analysis conducted shows that even though there are regulations related to constructive requirements that are based on optimizing the thermal resistance of walls, floors and ceilings, there exists a regulatory and calculation vacancy, in relation to thermal comfort in industrial buildings. Not only must the design parameters be taken into account, but also the type of activity, time range, time of year, and geographical region.

Although the Fanger's method was an important advance with respect to other indices of thermal comfort by including in the valuation, the variables that influence man-environment thermal exchanges (activity level, clothing characteristics, dry bulb temperature, relative humidity, average radiant temperature and air speed, it was developed in controlled chambers, with young people at rest, who had a European or North American origin (physiological model). Moreover, it does not contemplate the local thermal discomfort, real operating conditions or regional working habits. "Also, from this analysis, it is detected that the regulations do not take into account the qualitative approach and adaptation models" (Gómez-Azpeitia, L. et al, 2007).

Based on these considerations, some questions arise: what are the thermal comfort levels specific to real working conditions (time ranges / activities) and regional climatic ones? ; do these specific comfort levels improve working conditions? ; do they decrease the occupational risks?

\section{Objectives}

- Determine the regional thermal comfort levels for environmental conditions, time ranges and different types of activity.

- Select the best conditions of work comfort in terms of temperature, relative humidity, air speed according to the schedule and activity to be developed, in order to reduce the occupational risk. 


\section{Applied methodology and scope}

To assess these parameters, two case studies were conducted in Argentina, one for the Buenos Aires area and another for the Cuyo region (Benito, P. et al., 2018).

It consisted of applied research, using an empirical-analytical method. This investigation was carried out in different industries and companies, in enclosed spaces that could be conditioned. The variables taken into consideration were the external temperature of the dry bulb, the relative humidity, hourly and time of year, the type of activity with adequate clothing, and in "real work" conditions.

\subsection{The following hypotheses were proposed:}

- H1: The regional thermal comfort levels are specific for each activity, time ranges and time of year, according to the region.

- H2: The parameters of the regional thermal comfort levels applied to the calculation of the air conditioning facilities reduce the occupational risk and increase the performance

\subsection{The activities developed were:}

- Survey and registration in two stages: summer / winter.

- Analysis and statistical calculation.

- Preparation of tables and / or graphs of dry bulb temperature, relative humidity and air speed according to the type of work, comfort percentage, time range and time of year.

- Selection of an algorithm to determine the level of thermal comfort depending on the interior temperature, knowing the outside temperature, relative humidity, wind speed, latitude, longitude, type of activity and working hours .

- Contrast or refutation of hypotheses.

- Conclusions and recommendations.

\section{Results achieved}

The purpose was to obtain regional thermal comfort levels (internal temperature of dry bulb and relative humidity). By reproducing the results obtained using the air conditioning equipment existing in the workplace, it was possible to perform the test in a real environment. In the case of the Province of Buenos Aires and the Autonomous City (C.A.B.A.), the recommended values for the region, type of activity, and time of year are indicated in Table 1:

\begin{tabular}{|l|l|l|}
\hline Physical Work & Summer & Winter \\
\hline Slight & $26^{\circ} / 46 \%$ & $21 \% / 45 \%$ \\
\hline Moderate & $25^{\circ} / 50 \%$ & $20^{\circ} / 55 \%$ \\
\hline Strong & $22^{\circ} / 65 \%$ & $18,5^{\circ} / 48 \%$ \\
\hline
\end{tabular}

Tab.1. Recommended values for the Region of C.A.B.A and Buenos Aires 
Benito, P.; Gonzalez Gaya, C. \& Sebastian, M. A.: Thermal Industrial Comfort Ana...

In the case of Cuyo region, the values in Table 2 are those recommended for summer and in Table 3 those corresponding to winter.

\begin{tabular}{|l|l|l|}
\hline Activity & Temperature & Humidity \\
\hline Slight & $27,0^{\circ} \mathrm{C}$ & $63,0 \%$ \\
\hline Moderate & $24,5^{\circ} \mathrm{C}$ & $52,0 \%$ \\
\hline Strong & $22,0^{\circ} \mathrm{C}$ & $60,0 \%$ \\
\hline
\end{tabular}

Tab. 2. Recommended values for Cuyo Region in summer

\begin{tabular}{|l|l|l|}
\hline Activity & Temperature & Humidity \\
\hline Slight & $25,2^{\circ} \mathrm{C}$ & $46,8 \%$ \\
\hline Moderate & $24,0^{\circ} \mathrm{C}$ & $34,5 \%$ \\
\hline Strong & $23,0^{\circ} \mathrm{C}$ & $42,0 \%$ \\
\hline
\end{tabular}

Tab. 3. Recommended values for Cuyo Region in winter

When corroborating the benefits of using these recommended values for each type of activity and region, the value of having these comfort parameters for any geographic region was analyzed.

For this purpose, and as a starting point, data from Cuyo Region were used to obtain an algorithm that would provide the thermal comfort values for that region. To do so, the WEKA and Elvira software sets were used. "WEKA is a collection of automatic learning algorithms and data preprocessing." (Frank, E., Hall, M. and Witten, I., 2016, p.7). It was developed at the University of Waikato in New Zealand and contains tools for data reprocessing, classification, regression, clustering, association rules mining and visualization. It is open source issued under the GNU General Public License.

The Elvira software, a project funded by the Interministerial Commission of Science and Technology (CICYT) and the Ministry of Science and Technology of Spain, in which researchers from several Spanish universities participated, including the Universidad de Educación a Distancia (UNED), "is intended for the edition and evaluation of probabilistic graphic models, specifically Bayesian networks and influence diagrams". (Díez Vegas, F., 2010)

Firstly, the most relevant attributes were evaluated with WEKA and algorithm J 48 was selected with the following results: 


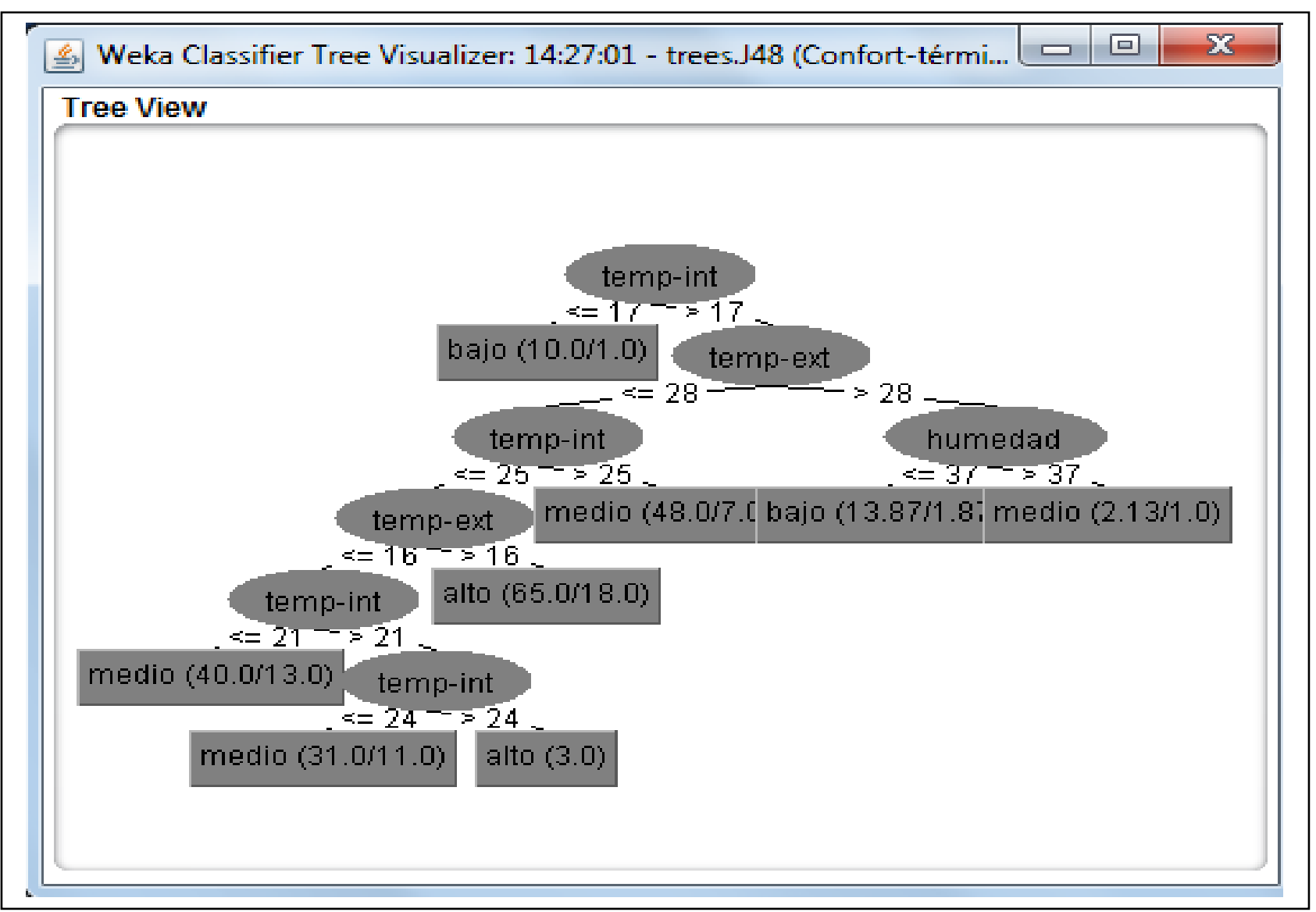

On the other hand, the data was evaluated with Elvira. Ranges of indoor and outdoor temperatures, humidity percentages, wind speed, latitude, longitude, type of activity and time of year were established in order to determine the thermal comfort level. When setting a variable, the others could be stated.

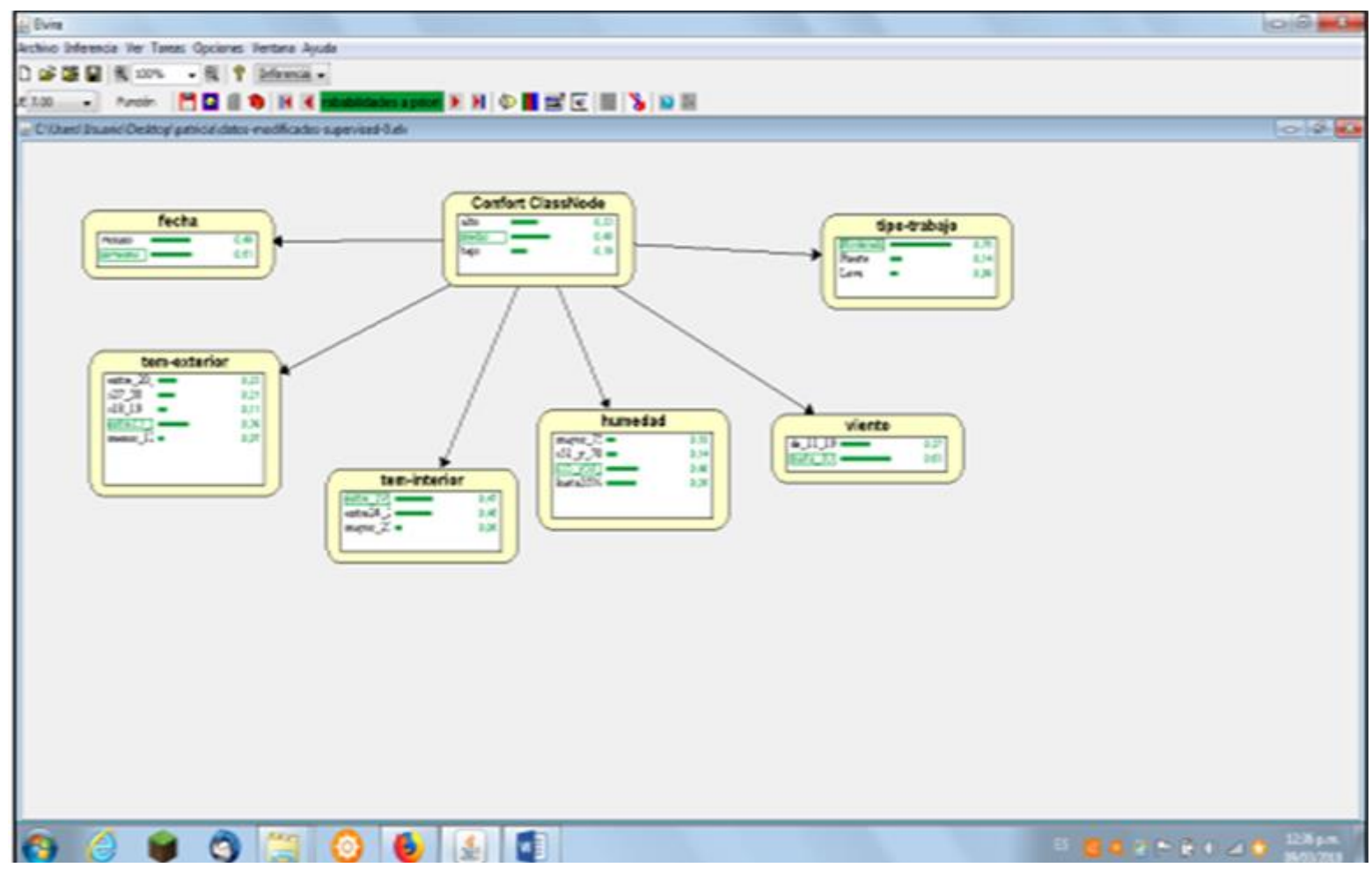


Benito, P.; Gonzalez Gaya, C. \& Sebastian, M. A.: Thermal Industrial Comfort Ana...

\section{Discussion and product}

In the summer period, it is observed that in the region of Buenos Aires the same degree of comfort is reached as in the Cuyo Region, with a lower indoor temperature (in general, they differ by $1^{\circ} \mathrm{C}$ ) when the relative humidity decreases.

For similar relative humidity, indoor temperatures also correspond to the type of work. In the winter period, it becomes clear that in the Cuyo region a higher indoor temperature is required for similar relative humidities, to obtain comparable degrees of comfort. These results may be affected by the greater variation of outdoor / indoor temperatures in the Cuyo region with respect to Buenos Aires.

From these data, it can be inferred that, at a lower relative humidity, a lower interior temperature is required to obtain comparable comfort states. If the outdoor / indoor temperature variations are very pronounced, the states of comfort are obtained by increasing the interior temperatures.

From the analysis of the data, the first hypothesis has been verified: "The regional thermal comfort levels are specific, that is, they depend on the activity and the time ranges of the region under consideration." It remains to verify the second hypothesis.

In addition, and to generalize the results of this research to any geographic region, the data obtained with the software Weka and Elvira were evaluated to select an algorithm that allows to determine the thermal comfort level, depending on the indoor temperature knowing the external temperatures, relative humidity, wind speed, latitude, longitude, type of activity and working hours.

The achievement of this product will be of great interest to the designers of the air conditioning facilities and to the professionals of Occupational Safety and Health and will benefit the companies and/or industries, mainly their staff who, in fact, happens to be the most important beneficiary.

The selected algorithms have been contrasted with the data of the Cuyo Region. In a next stage, it is expected to contrast the data provided from any region of Argentina.

\subsection{The expected benefits are:}

- Better work climate.

- Greater energy efficiency

- Higher productivity

- Better life quality.

\section{Acknowledgements}

The authors thank the International Doctoral School of the UNED (EIDUNED), especially the Department of Construction and Manufacturing Engineering. Also, thank the Secretariat of Science and Technology of the Universidad de Morón for its support through the 2016-PID01-002 project. 


\section{References}

Benito, P. et al. (2018). Climate Change, Environment and Biosphere: Thermal Comfort Levels- Revista de investigaciones científicas de la Universidad de Morón, 2 (3), 45-49.https://doi.org/10.34073/36

Blasco Laffón, B., Blasco Laffón, E., Fernández Valdés, J. M., and Viñas Arrebola, C. (2007). Calculation of thermal comfort indexes in closed rooms with heat transfer. Retrieved from http://oa.upm.es/3676/2/LAFFON_PON_2007_01.pdf

Brager, G. \& De Dear, R. (1998). Thermal adaptation in the built environment: a literatura review- Energy and Building, number27, pp 83-96. ISSN 0378-7788

Brager, G.S.; Zhang, H. \& Arens, E., (2015): Evolving opportunities for providing thermal comfort. Building Research \&Information,43 (3), 274-287

Castejón, E. (1983). Documentation NTP 74: Thermal comfort - Hazard method for its evaluation. Prevention Technical Notes. INSHT, 1-14.

Clausen, G. \& Fanger, P.O. (2004) Impact of indoor air temperature and humidity in an office on perceived air quality, SBS symptoms and performance. Indoor Air Journal 14(Suppl 7) pp.74-81.

d'Ambrosio Alfano, F.R.; Palalla, B.I. \& Riccio, G. (2011) Thermal Environment Assessment Reliability Using Temperature-Humidity Indices, in: Industrial health, 49, pp. 95-106. ISSN: 0019-8366.

Fanger, P. O. (2008). Assessment of man's thermal comfort in practice. Occupational and Environmental Medicine, 30(4), 313-324. https://doi.org/10.1136/oem.30.4.313

Frank, E. et al, (2016), The Weka Workbench, Online Appendix for "Data Mining: Practical Machine Learning Tools and Techniques", Morgan Kaufmann, Fourth Edition.

Gómez-Azpeitia, 1 et al, 2007. Dos enfoques teóricos enfrentados. Buildings, núm. 27, pp. 83-96. Thermal comfort: two confronted theoretical focuses. Retrieved from https://www.researchgate.net/publication/285832706_El_confort_termico_Dos_enfo ques_teoricos

Hernández, A. (1998). NTP 501: Thermal environment: local thermal failure. National Institute for Safety and Hygiene at Work. https://doi.org/10.1007/s00383-008-2109-9 Hernández Calleja, A. (2007). NTP 779: Thermal wellbeing: design criteria for comfortable thermal environments. National Institute for Safety and Hygiene at Work Humphreys, M. (1976). Field studies of thermal comfort compared and applied, J. Inst. Heat. \&Vent. Eng. 44, pp. 5-27.

Humphreys, M. \& Nicol, F. (2007). Self-assessed productivity and the office environment: Monthly surveys in five European countries. ASHRAE Transactions. 113. 606-616.://www.cs.waikato.ac.nz/ml/weka/citing.html

ISO. (2005). Reference number ISO 7730: 2005 (E) (C) ISO 2005 INTERNATIONAL STANDARD ISO 7730 Third edition 2005-11-15. Ergonomics of the thermal environment: analytical determination and interpretation of thermal comfort by calculating the PMV and PPD indices and the local thermal comfort criteria (Vol. 2005) Jirak, Z., et al., (2012) New Approach to assessing thermal humidity conditions in workplaces. In: Practice of Medicine. 64, 2012, No. 1, p. 23-31. ISSN 0032-6291. 
Benito, P.; Gonzalez Gaya, C. \& Sebastian, M. A.: Thermal Industrial Comfort Ana...

Kralikova, R[uzena] \&Wessely, E[mil] (2018). Impact of the Environmental Factors and its Effects on productivity and Health, Proceedings of the 29th DAAAM International Symposium, pp.0119-0124, B. Katalinic (Ed.), Published by DAAAM International, ISBN 978-3-902734-20-4, ISSN 1726-9679, Vienna, Austria DOI: 10.2507/29th.daaam.proceedings.016

Law 31/1995 of November 8 on Prevention of Occupational Risks-BOE 269, of November 10, 1995- Last modification: December 29, 2014 (Reference: BOE-A-199524292) - Edition updated at 13 March 2019.

Law No. 4458 on Standards of thermal conditioning in building construction. Retrieved from http://www2.cedom.gob.ar/es/legislacion/normas/leyes/ley4458.html on April 10,2019

Law 13059/03 on Energy Saving of the Province of Buenos Aires, regulated by Decree No. 1030/10. Retrieved from https://www.scribd.com/document/357523327/LeyAhorro-Energetico-Provincia-de-Bs-as-Ley-13059-03-Decreto-1030-10 on April 24, 2019

Law No. 19587 on Occupational Safety and Health. Retrieved from http://servicios.infoleg.gob.ar/infolegInternet/anexos/15000-19999/17612/norma.html on April 17, 2019

National Institute for Occupational Safety and Health, NTP 74, 1983, Thermal comfort - Fanger method for evaluation. Retrieved from http://intranet.insht.es/InshtWeb/Contenidos/Documentacion/FichasTecnicas/NTP/Fi cheros/001a100/ntp_074.pdf on February 2, 2019

National Institute of Safety and Hygiene at work, NTP 501, 1998, Thermal environment and local thermal insufficiency.1998. Retrieved on February 2, 2019 http://www.insht.es/InshtWeb/Contenidos/Documentacion/FichasTecnicas/NTP/Fich eros/501a600/ntp_501.pdf

Occupational Risk Prevention Law (LPRL) - Ministry of Labor and Social Affairs: Royal Decree 486/1997, of April 14, (BOE of April 23, 1997). Retrieved from https://www.boe.es/legislacion/codigos/codigo.php?id=037_Prevencion_de_riesgos_1 aborales on March 2, 2019

Regulatory Decree No. 351/79. Retrieved from http://servicios.infoleg.gob.ar/infolegInternet/anexos/30000-34999/32030/texact.htlm on April 172019

Regulation of Thermal Installations in Buildings (RITE), 2007-BOE 207-Retrieved from https://www.boe.es/buscar/doc.php?id=BOE-A-2007-15820.

Sun, C., Lian, Z., Lan, L., and Zhang, H. (2013). Research on the temperature range for thermal comfort in non-uniform environments. HVAC and R Research, 19 (2), 103112. https://doi.org/10.1080/10789669.2012.744927.

Yang, Rui-Liang; Liu, Lei \& Zhou, Yi-De (2015): Predicted Thermal Sensation Index for the Hot Environment in the Spinning Workshop. Mathematical problems in engineering.

***http://www.ia.uned.es/ fjdiez/bayes/elvira/manual/manual.html ***http://www.cs.waikato.ac.nz/ml/weka/citing.html 